NBER WORKING PAPER SERIES

TESTING THE THEORY OF MULTITASKING:

EVIDENCE FROM A NATURAL FIELD EXPERIMENT IN CHINESE FACTORIES

\author{
Fuhai Hong \\ Tanjim Hossain \\ John A. List \\ Migiwa Tanaka
}

Working Paper 19660

http://www.nber.org/papers/w19660

\author{
NATIONAL BUREAU OF ECONOMIC RESEARCH \\ 1050 Massachusetts Avenue \\ Cambridge, MA 02138 \\ November 2013
}

We thank Aureo de Paula, Florian Englmaier, Ying Fan, April Franco, Avi Goldfarb, Matthew Grennan, Nicola Lacetera, Magne Mogstad, Justin Sydnor, and seminar participants at the Singapore Economic Review Conference, University College London, University of Toronto, University of Konstanz, University of Western Ontario, and Industrial Organization Society for helpful comments. We gratefully acknowledge the financial support of SSHRC Grant No. 489160, and financial support from Shanghai University of Finance and Economics. All correspondence should be directed to Tanjim Hossain (tanjim.hossain@utoronto.ca). The views expressed herein are those of the authors and do not necessarily reflect the views of the National Bureau of Economic Research.

NBER working papers are circulated for discussion and comment purposes. They have not been peerreviewed or been subject to the review by the NBER Board of Directors that accompanies official NBER publications.

(C) 2013 by Fuhai Hong, Tanjim Hossain, John A. List, and Migiwa Tanaka. All rights reserved. Short sections of text, not to exceed two paragraphs, may be quoted without explicit permission provided that full credit, including $\odot$ notice, is given to the source. 
Testing the Theory of Multitasking: Evidence from a Natural Field Experiment in Chinese Factories

Fuhai Hong, Tanjim Hossain, John A. List, and Migiwa Tanaka

NBER Working Paper No. 19660

November 2013

JEL No. C9,C90,C93,D01,D22

\begin{abstract}
A well-recognized problem in the multitasking literature is that workers might substantially reduce their effort on tasks that produce unobservable outputs as they seek the salient rewards to observable outputs. Since the theory related to multitasking is decades ahead of the empirical evidence, the economic costs of standard incentive schemes under multitasking contexts remain largely unknown. This study provides empirical insights quantifying such effects using a field experiment in Chinese factories. Using more than 2200 data points across 126 workers, we find sharp evidence that workers do trade off the incented output (quantity) at the expense of the non-incented one (quality) as a result of a piece rate bonus scheme. Consistent with our theoretical model, treatment effects are much stronger for workers whose base salary structure is a flat wage compared to those under a piece rate base salary. While the incentives result in a large increase in quantity and a sharp decrease in quality for workers under a flat base salary, they result only in a small increase in quantity without affecting quality for workers under a piece rate base salary.
\end{abstract}

\section{Fuhai Hong}

Division of Economics

Nanyang Technological University

fhhong@ntu.edu.sg

Tanjim Hossain

Rotman School of Management, University of Toronto

tanjim.hossain@utoronto.ca
John A. List

Department of Economics

University of Chicago

1126 East 59th

Chicago, IL 60637

and NBER

jlist@uchicago.edu

Migiwa Tanaka

Department of Economics

University of Toronto

migiwa.tanaka@utoronto.ca 


\section{Introduction}

One ubiquitous feature of modern economies is the importance of principal-agent relations. Be it at home, at school, in the board room, or in the doctor's office, each contains significant components of the principal-agent relationship. The general structure of the problem is that the agent has better information about her actions than the principal and, without proper incentives, inefficient outcomes are obtained. For instance, a worker in a firm usually knows more about how hard he is working and how such effort maps into productivity than does the owner. A particularly important and relatively complex problem arises when output has multiple dimensions that vary in their quantifiability.

The core principle of the multitasking theory initiated by Holmstrom and Milgrom (1991) is that agents will focus their effort on measurable and rewarded tasks at the expense of other tasks (when higher effort on one task raises the marginal cost of effort on other tasks), potentially adversely influencing the principal's benefits. Therefore, it is desirable for the principal to keep a balance between incentives across tasks to avoid this form of "task arbitrage" by the agent. Ever since the seminal work of Holmstrom and Milgrom (1991), theorists have made important advances related to the multitasking problem and its relation to contract theory (see, Prendergast (1999) for an excellent review).

Multitasking is a major component of a recent policy debate concerning pay for performance to doctors in New York City public hospitals (see Hartocolis, 2013 and Keller, 2013). While doctors will receive raises based on some quality measures, such as patients' ratings of doctors' communication effort, promptness in operation room, and the speed of service, many other quality aspects of health care will not be measured. If predictions from the multitasking theory bear out in practice, qualities of the rewarded measures are likely to increase as a result of the pay for performance scheme, but that may have adverse effect on the unmeasured quality dimensions. Such concerns will affect how optimal contracts should be written between hospitals and physicians.

Understanding how given incentive contracts affect agents' effort choice in observed and unobserved dimensions is a necessary first step in the study of contract design under multitasking. While the import of the topic is hard to understate, what is clear is that empirical work is decades behind the theory. Yet, there have been some recent novel efforts to rectify this situation. For 
example, using observational data, Marschke (1996), Paarsch and Shearer (2004), Dumont et al. (2008), Johnson, Reiley, and Munoz (2012), and Lu (2012) generally find support for the received theory. Al-Ubaydli et al (2008) also find that worker responses are largely consonant with theory in their natural field experiment. Although not aiming to test the multitasking theory directly, field experiments of Shearer (2004), Bandiera, Barankay, and Rasul (2005), and Hossain and List (2012) do not find that the quality of work is affected by the incentives in the quantity of production. Similarly, Englmaier, Roider, and Sunde (2013) find that making the piecewise wage rate more salient to the workers increase productivity but does not affect the quality of production significantly. Alternatively, Hossain and Li (2013) find that workers reciprocate to a high piece rate wage by increasing the quality of work even though their income does not depend on the quality. There have been even fewer empirical or experimental studies on how multitasking issues affect contracts. One notable exception is Slade (1996), who studies how complementarity between different tasks affects incentive contracts in a vertical relationship.

In most of the above studies, while output levels in certain dimensions are not contracted upon, the agents know that output levels in those dimensions can be observed by the principal. ${ }^{1}$ Moreover, the principal and the agents are engaged in long term contracts. As a result, workers or the agents may incorporate that into their objective function even if those dimensions are not incentivized in the contract and may not necessarily behave according to the predictions of Milgrom and Holmstrom (1991). Such a repeated-game effect compounds the problem of testing the multitasking theory, which is originally based on a one-shot interaction model.

In this study, we take the literature in a new direction by visiting Chinese factories. By overlaying a field experiment in a natural setting, we can explore how regular factory workers respond to incentives in a multitask environment and quantify the effect of such incentives on output dimensions that are both contracted and not contracted. Specifically, we choose work where the quality of the produced goods is lightly inspected. More importantly, the settings of these inspections are such that the exact worker who produced the product is not identified during the sample inspection. During our experiment, we hired inspectors who secretly inspected the quality of each produced unit while identifying who produced each product. Even

\footnotetext{
${ }^{1}$ In Al-Ubaydli et al (2008), however, the temporary workers were not aware that the employer would observe the quality of their work.
} 
though we have perfect measure for the quality of production, from the workers' points of view, quality is unobservable to the principal. Reputation concerns arising from observability of outputs and long-term interactions between the principal and the agent are unlikely to affect an agent's effort choice in the quality dimension. Thus, we created an ideal setting to test predictions from the multitasking theory where production quality is not observable. ${ }^{2}$

Our experimental testing ground is five firms located on the southern side of Fujian, a southeastern coastal province of China with a high concentration of manufacturers of electronics and clocks and watches. These five firms allowed us to introduce treatments to induce greater production levels of GPS devices, alarm devices, and clocks. Importantly, before our intervention, the base salary structure of workers in some of the factories is a flat per hour wage, whereas in some of the factories the workers are paid with piece rates. Our key experimental treatment revolves around workers' pay: during the incentive treatment, workers received monetary incentives based on their observed productivity in addition to their base salary, whereas under the control they did not receive any additional monetary incentive. The monetary incentives were approximately $40 \%$ of base salary. Using a data set with more than 2200 observations across 126 workers, we report several insights.

First, we find that our incentives worked: compared to their baseline productivity, the workers increased their productivity by $25.6 \%$ on average, when they received monetary incentives. There is, however, an important caveat to our first finding: incentives work, but it is much stronger for workers who were not incented on the margin in their naturally-occurring jobs. Those workers whose base salaries are paid with fixed hourly wages showed very large incentive effects (50.1\%) whereas those whose base salaries are paid by piece rates showed statistically significant but smaller effects (4.9\%). This result suggests that the workers who are incented on the margin under their base salary produced near their individual production frontiers before the experiment whereas those not incented on the margin were far from their personal frontiers. This is also consistent with predictions from our simple theoretical model.

\footnotetext{
${ }^{2}$ Jensen (2001) and Griffith and Neely (2009) investigate the profitability of paying incentives based on overall performance measures. In this paper, we do not investigate the profitability of specific performance pay schemes, which is more difficult to generalize. Rather, we ask the more general question of whether performance pay based on observed effort dimensions leads to substitution of unobserved efforts.
} 
Second, we also observe a difference in defect rates between treatments: although workers increased productivity as a result of the monetary inducement, their quality of production decreased, as predicted by standard theory. Specifically, we find that the workers increase their defect rates by $61.3 \%$, under the bonus scheme. Analyzing the relation between productivity and the defect rate, we find that a $1 \%$ increase in the hourly productivity comes with a $1.87 \%$ increase in the defect rate. This result means that workers in our field experiment did not reciprocate to the generous bonus scheme that we provided by increasing the quality of production. In fact, it was quite the opposite: even though workers knew that quality was important, they shirked on that dimension to earn greater financial rewards. Interestingly, further analysis of the data suggests that the quantity-quality trade-off is present only for workers under a flat rate base salary. The bonus scheme is associated with a $97.2 \%$ increase in the defect rates for workers under a flat rate base salary. However, the increase in the defect rate is not statistically significant (with a much smaller coefficient) for workers under a piece rate base salary. Thus, while workers under a flat rate base salary clearly substituted effort in the unobservable dimension with effort in the observable dimension, such effects seem much weaker for workers under a piece rate base salary. An implication for researchers and policymakers is that great care must be taken when generalizing results on introduction of incentives because the extant economic environment can greatly influence observed treatment effects.

Finally, our data from the control groups show the importance of a Hawthorne effect. Even though the actual Hawthorne data from the original experiments do not stand up to closer scrutiny (see Levitt and List, 2011), the data from Chinese factories do: we find a robust and economically significant Hawthorne effect in Chinese manufacturing plants. The measured effect is large — around 9\% — and is temporally resilient: it lasts for the entire experimental session.

The remainder of our paper proceeds as follows. The next section outlines the theoretical framework for our design. Sections III and IV describe the experimental design and the main results, respectively. Section $\mathrm{V}$ discusses the extent of the Hawthorne effect in our data and Section VI concludes. 


\section{Theoretical Framework}

In what follows, we outline a basic form of the multitasking theory based on Holmstrom and Milgrom (1991) and Baker (1992). In this model, an agent chooses a level of effort $e=\left(e_{1}\right.$, $e_{2}$ ) to provide to a task given by a principal, where $e$ is two-dimensional. Intuitively, we can think that the first dimension of effort affects the quantity of output and the second dimension affects the quality of output. The quantity and quality are, respectively, given by the production functions $f\left(e_{1}\right)$ and $d\left(e_{2}\right)$, which are both strictly increasing. ${ }^{3}$ However, incentive contracts can be based only on $f\left(e_{1}\right)$ as the principal only observes the quantity of production. Without loss of generality, we assume that $f\left(e_{1}\right)=e_{1}$ and $d\left(e_{2}\right)=e_{2}$. To provide effort level of $e$, we assume that an agent faces an effort cost of $C(e)$. We impose a standard set of regularity conditions on $C(e)$, namely that:

- $\quad C(e)$ is strictly convex and is continuously differentiable on its domain and

- $C_{12}(e)$ is strictly positive on its domain. Here subscripts of 1 and 2 denote partial derivatives with respect to $e_{1}$ and $e_{2}$, respectively.

As in Holmstrom and Milgrom (1991), C(e) attains an interior minimum at some finite, strictly positive vector $\bar{e}=\left(\overline{e_{1}}, \overline{e_{2}}\right)$, representing the effort choice of the agent when neither dimension of effort is incentivized. We assume that $\bar{e}$ is strictly positive due to concerns for the employer or the firm, disutility from boredom if the agent exerts no effort, etc. The assumption that $C_{12}$ is strictly positive implies that increasing effort in one dimension increases the marginal cost in the other dimension of effort. Thus, increasing effort in one dimension leads to some negative externality on the other dimension.

In this context, the principal offers the agent a wage of $\gamma+\alpha_{0} e_{1}$ where $\gamma$ is a fixed payment and $\alpha_{0} \geq 0$ is piece rate payment on the observable component of effort. In this paper, we do not investigate how the principal chooses such a contract. Rather, we focus solely on how the agent responds to a given wage contract. Given the wage offer, the agent will choose her effort level $e^{*}$ such that:

$$
e^{*}=\max _{e} \gamma+\alpha_{0} e_{1}-C(e) .
$$

From this model, we would predict that an agent who is offered a flat rate of pay, $\alpha_{0}=0$ (i.e. not incented on the margin), would choose the interior minimum level of effort $\bar{e}$. In addition, since

\footnotetext{
${ }^{3}$ Theory models solving for optimal contracts often assume that there are unobservable shocks in the production functions. However, for our purpose of understanding agent behavior, deterministic production functions suffice.
} 
we assumed that $e_{1}$ and $e_{2}$ are substitutes in the agent's effort, we predict that when facing a piece rate $\alpha_{0}>0$, the agent will increase effort on the observable component of effort while reducing effort on the unobservable component of effort. This follows from the fact that reducing $e_{2}$ reduces the marginal cost of increasing $e_{1}$. These results are reported in Lemma 1.

Lemma 1 An agent facing a contract where $\alpha_{0}$ equals 0 will respond by choosing $e^{*}=\bar{e}$. Moreover, the larger the value of $\alpha_{0}$ is, the larger will be the agent's choice of $e_{1}$ and the smaller will be her choice of $e_{2}$ when she maximizes her payoff.

Proof: If $\alpha_{0}=0$, then the agent will choose $e^{*}$ such that $C_{1}\left(e^{*}\right)=C_{2}\left(e^{*}\right)=0$. However, that implies that $e^{*}$ is the unique interior minimizer for the function $C$. In other words, $e^{*}=\bar{e}$. In general, the agent solves the following maximization problem: $\max \alpha_{0} e_{1}-C(e)$. First order conditions imply that at the optimal level of effort $e^{*}, C_{1}\left(e^{*}\right)=\alpha_{0}$ and $C_{2}\left(e^{*}\right)=0$. Total differentiation of these two conditions yields $C_{11} d e_{1}+C_{12} d e_{2}-d \alpha_{0}=0$ and $C_{21} d e_{1}+$ $C_{22} d e_{2}=0$. The second condition implies that $d e_{2}=-\frac{C_{12}}{C_{22}} d e_{1}$. Inserting this in the first condition, we get $C_{11} d e_{1}-\frac{C_{12}^{2}}{C_{22}} d e_{1}=d \alpha_{0} \Rightarrow \frac{d e_{1}}{d \alpha_{0}}=\frac{C_{22}}{C_{11} C_{22}-C_{12}^{2}}$. Now, $C_{22}>0$ and $C_{11} C_{22}-$ $C_{12}^{2}>0$ because $C$ is strictly convex. Hence, $\frac{d e_{1}}{d \alpha_{0}}>0$. Moreover, $\frac{d e_{2}}{d \alpha_{0}}=\frac{d e_{2}}{d e_{1}} \frac{d e_{1}}{d \alpha_{0}}=-\frac{C_{12}}{C_{22}} \frac{d e_{1}}{d \alpha_{0}}<0$. Therefore, as $\alpha_{0}$ increases, the chosen level of effort increases in the first dimension and decreases in the second dimension."

Lemma 1 implies that compared to an agent receiving a flat wage rate, an agent under a piece rate contract will put in more effort in the quantity dimension and exert less effort in the quality dimension. ${ }^{4}$ We see the multitasking problem that the principal faces from this result. On one hand, offering no incentive at the margin may lead the agent to choose effort level $e^{*}=\bar{e}$ which is suboptimal for the principal. On the other hand, if the second component of effort is sufficiently important, the principal may not be able to improve upon the agent's choice of $\bar{e}$.

Now we analyze the impact of a piece rate bonus on top of the base salary of $\gamma+\alpha_{0} e_{1}$. Specifically, a worker who produces $e_{1}$ units receives a bonus of $\alpha_{1}\left(e_{1}-e_{1 t}\right)$ when she produces

\footnotetext{
${ }^{4}$ We get the same theoretical prediction if we assume that the production functions $f$ and $d$, instead of the cost function $C$, depend on efforts in both dimensions. Specifically, suppose that fixing $e_{1}$, increasing $e_{2}$ reduces quantity while increasing quality. On the other hand, if $e_{2}$ is fixed, increasing $e_{1}$ increases quantity and decreasing quality. The agent's strategic trade-offs in this model are fundamentally the same as those in our model above. In both cases, agents strategically increase $e_{1}$ and reduce $e_{2}$ as a result of a quantity-based bonus when quality is unobserved.
} 
$e_{1}>e_{1 t}$ for a set target level $e_{1 t} \geq 0$ with $\alpha_{1}>0$. That is, the agent producing $e_{1}$ units will earn a wage of $w$ where $w= \begin{cases}\gamma+\alpha_{0} e_{1} & \text { if } e_{1} \leq e_{1 t} \\ \gamma+\alpha_{0} e_{1}+\alpha_{1}\left(e_{1}-e_{1 t}\right) & \text { if } e_{1}>e_{1 t}\end{cases}$

For workers with a flat rate base salary, $\alpha_{0}=0$ and for workers with a piece rate base salary, $\alpha_{0}>0$. We use Lemma 1 to show the first prediction of the multitasking theory that we test. The introduction of a piece rate bonus will (weakly) increase effort in the quantity dimension and (weakly) decrease effort in the quality dimension under both flat rate and piece rate base salaries. For the rest of this section, we assume that $\alpha_{1}$ is high enough and $e_{1 t}$ is low enough such that the agent chooses $e_{1}$ larger than $e_{1 t}$ when she is offered the bonus scheme. Of course, if this is not true, the bonus will not have an effect on the agent's effort choice and she will produce below $e_{1 t}$ with or without the bonus scheme.

Proposition 1 Suppose that $\alpha_{1}$ is high enough and $e_{1 t}$ is low enough such that the agent chooses $e_{1}$ larger than $e_{1 t}$ when she is offered the bonus scheme. Then, she will increase $e_{1}$ and decrease $e_{2}$ under the bonus scheme.

Proof: Suppose that the agent chooses the effort vectors $e^{\prime}$ and $e^{\prime \prime}$ under the base salary and the bonus scheme, respectively. Since we assumed that the chosen level of $e_{1}$ is larger than $e_{1 t}$ under the bonus scheme, the first order conditions are: $C_{1}\left(e^{\prime}\right)=\alpha_{0}, C_{1}\left(e^{\prime \prime}\right)=\alpha_{0}+\alpha_{1}$ and $C_{2}\left(e^{\prime}\right)=$ $C_{2}\left(e^{\prime \prime}\right)=0$. Here $\alpha_{0} \geq 0$ and $\alpha_{1}>0$. Thus, one can view the bonus scheme to be an incentive scheme that offers a larger piece rate at the margin. Following Lemma $1, e_{1}^{\prime \prime}>e_{1}^{\prime}$ and $e_{2}^{\prime \prime}<e_{2}^{\prime}$.

We can further show that under suitable conditions, the increase in effort in the quantity dimension will be smaller as $\alpha_{0}$ increases for a given $\alpha_{1}$. For this result, we make a number of new assumptions on the marginal cost functions $C_{1}$ and $C_{2}$. First, the cross partial derivatives of $C_{1}$ and $C_{2}$ equal zero; that is $C_{112}=C_{221}=0$. Thus, $C_{11}$ and $C_{22}$ are independent of the value of $e_{2}$ and $e_{1}$, respectively. Moreover, we assume that $C_{111}>0$ and $C_{222}>0$ and $\frac{C_{111}}{C_{222}}>\frac{C_{11} C_{12}}{C_{22}^{2}}$ for all $e$. Thus, the marginal costs are convex and, in some sense, $C_{1}$ is sufficiently more convex than $C_{2}$. These assumptions lead to the following proposition. 
Proposition 2 For a given $\alpha_{1}$, the larger the value of $\alpha_{0}$ is, the smaller will be the magnitudes of the increase in $e_{1}$ and the decrease in $e_{2}$ as a result of the bonus.

Proof: Suppose that the agent chooses the effort vectors $e^{\prime}$ and $e^{\prime \prime}$ under the base salary and the bonus scheme, respectively. The first order conditions are: $C_{1}\left(e^{\prime}\right)=\alpha_{0}, C_{1}\left(e^{\prime \prime}\right)=\alpha_{0}+\alpha_{1}$ and $C_{2}\left(e^{\prime}\right)=C_{2}\left(e^{\prime \prime}\right)=0$. We need to show that $\frac{d\left(e_{1}^{\prime \prime}-e_{1}^{\prime}\right)}{d \alpha_{0}}<0$ and $\frac{d\left(e_{2}^{\prime}-e_{2}^{\prime \prime}\right)}{d \alpha_{0}}<0$. Recall that, Lemma 1 implies that the larger $\alpha_{0}$ is, the larger will be $e_{1}^{\prime}$ and the smaller will be $e_{2}^{\prime}$. Therefore, it is sufficient to show that $\frac{d\left(e_{1}^{\prime \prime}-e_{1}^{\prime}\right)}{d e_{1}^{\prime}}<0$ and $\frac{d\left(e_{2}^{\prime \prime}-e_{2}^{\prime}\right)}{d e_{2}^{\prime}}<0$. The first order conditions imply that $C_{1}\left(e^{\prime \prime}\right)-C_{1}\left(e^{\prime}\right)=\alpha_{1}$. Using total differentiation and the fact that $\alpha_{1}$ is kept unchanged, we can show that

$$
C_{11}\left(e^{\prime \prime}\right) d e_{1}^{\prime \prime}+C_{12}\left(e^{\prime \prime}\right) d e_{2}^{\prime \prime}-C_{11}\left(e^{\prime}\right) d e_{1}^{\prime}-C_{12}\left(e^{\prime}\right) d e_{2}^{\prime}=0 .
$$

Total differentiations of the first order conditions on $C_{2}$ gives us $d e_{2}=-\frac{C_{12}}{C_{22}} d e_{1}$ for both $e^{\prime}$ and $e^{\prime \prime}$. Inserting these values in equation (1), we get

$$
\begin{gathered}
C_{11}\left(e^{\prime \prime}\right) d e_{1}^{\prime \prime}-\frac{C_{12}^{2}\left(e^{\prime \prime}\right)}{C_{22}\left(e^{\prime \prime}\right)} d e_{1}^{\prime \prime}=C_{11}\left(e^{\prime}\right) d e_{1}^{\prime}-\frac{C_{12}^{2}\left(e^{\prime}\right)}{C_{22}\left(e^{\prime}\right)} d e_{1}^{\prime} \\
\Rightarrow \frac{d e_{1}^{\prime \prime}}{d e_{1}^{\prime}}=\frac{\frac{C_{11}\left(e^{\prime}\right) C_{22}\left(e^{\prime}\right)-C_{12}^{2}\left(e^{\prime}\right)}{C_{22}\left(e^{\prime}\right)}}{\frac{C_{11}\left(e^{\prime \prime}\right) C_{22}\left(e^{\prime \prime}\right)-C_{12}^{2}\left(e^{\prime \prime}\right)}{C_{22}\left(e^{\prime \prime}\right)}}
\end{gathered}
$$

By strict convexity of $C$, both the numerator and denominator in the right side of Equation (2) are positive. Then, showing that $C_{11}\left(e^{\prime \prime}\right)-\frac{C_{12}^{2}\left(e^{\prime \prime}\right)}{C_{22}\left(e^{\prime \prime}\right)}>C_{11}\left(e^{\prime}\right)-\frac{C_{12}^{2}\left(e^{\prime}\right)}{C_{22}\left(e^{\prime}\right)}$ will be sufficient for showing that $\frac{d e_{1}^{\prime \prime}}{d e_{1}^{\prime}}<1$ and the increase in effort in dimension 1 due to the bonus scheme is decreasing in $\alpha_{0}$. Let us define $G(e)=C_{11}(e)-\frac{C_{12}^{2}(e)}{C_{22}(e)}$. Then,

$$
\begin{gathered}
d G=C_{111} d e_{1}+C_{112} d e_{2}-\frac{2 C_{12} C_{112} C_{22}-C_{12}^{2} C_{122}}{C_{22}^{2}} d e_{1}-\frac{2 C_{12} C_{122} C_{22}-C_{12}^{2} C_{222}}{C_{22}^{2}} d e_{2} \\
=C_{111} d e_{1}+\frac{C_{12}^{2} C_{222}}{C_{22}^{2}} d e_{2}=\left(C_{111}-\frac{C_{12}^{3} C_{222}}{C_{22}^{3}}\right) d e_{1} .
\end{gathered}
$$


Note that the above uses our assumption that the third-order cross partial derivatives (e.g. $C_{112}$, $C_{221}$, etc.) equal zero. Now, strict convexity of $C$ implies that $C_{11} C_{22}>C_{12}^{2} \Rightarrow C_{11} C_{12}>\frac{C_{12}^{3}}{C_{22}}$ and we assumed that $\frac{C_{111}}{C_{222}}>\frac{C_{11} C_{12}}{C_{22}^{2}}$. Therefore, $\frac{C_{111}}{C_{222}}>\frac{C_{12}^{3}}{C_{22}^{3}}$. Since $e_{1}^{\prime \prime}>e_{1}^{\prime}$, this implies that $G\left(e^{\prime \prime}\right)>$ $G\left(e^{\prime}\right)$ and $\frac{d e_{1}^{\prime \prime}}{d e_{1}^{\prime}}<1 \Rightarrow \frac{d\left(e_{1}^{\prime \prime}-e_{1}^{\prime}\right)}{d e_{1}^{\prime}}<0$.

To prove the part for $e_{2}$, we substitute $d e_{1}=-\frac{C_{22}}{C_{12}} d e_{2}$ into Equation (1), which yields

$$
C_{12}\left(e^{\prime \prime}\right) d e_{2}^{\prime \prime}-\frac{C_{11}\left(e^{\prime \prime}\right) C_{22}\left(e^{\prime \prime}\right)}{C_{12}\left(e^{\prime \prime}\right)} d e_{2}^{\prime \prime}=C_{12}\left(e^{\prime}\right) d e_{2}^{\prime}-\frac{C_{11}\left(e^{\prime}\right) C_{22}\left(e^{\prime}\right)}{C_{12}\left(e^{\prime}\right)} d e_{2}^{\prime}
$$

and therefore

$$
\frac{d e_{2}^{\prime \prime}}{d e_{2}^{\prime}}=\frac{C_{12}\left(e^{\prime}\right)-\frac{C_{11}\left(e^{\prime}\right) C_{22}\left(e^{\prime}\right)}{C_{12}\left(e^{\prime}\right)}}{C_{12}\left(e^{\prime \prime}\right)-\frac{C_{11}\left(e^{\prime \prime}\right) C_{22}\left(e^{\prime \prime}\right)}{C_{12}\left(e^{\prime \prime}\right)}} .
$$

Define $H(e)=C_{12}(e)-\frac{C_{11}(e) C_{22}(e)}{C_{12}(e)}$. Given our assumptions,

$$
\begin{aligned}
d H=C_{121} d e_{1} & +C_{122} d e_{2}-\frac{C_{111} C_{22} C_{12}+C_{11} C_{221} C_{12}-C_{11} C_{22} C_{121}}{C_{12}^{2}} d e_{1} \\
& -\frac{C_{112} C_{22} C_{12}+C_{11} C_{222} C_{12}-C_{11} C_{22} C_{122}}{C_{12}^{2}} d e_{2}=\left(\frac{C_{111} C_{22}^{2}}{C_{12}^{2}}-\frac{C_{11} C_{222}}{C_{12}}\right) d e_{2} .
\end{aligned}
$$

Our assumption $\frac{C_{111}}{C_{222}}>\frac{C_{11} C_{12}}{C_{22}^{2}}$ implies that $\frac{C_{111} C_{22}^{2}}{C_{12}^{2}}>\frac{C_{11} C_{222}}{C_{12}}$. Then, $0>H\left(e^{\prime}\right)>H\left(e^{\prime \prime}\right)$ since $e_{2}^{\prime}>e_{2}^{\prime \prime}$. As a result, $\frac{d e_{2}^{\prime \prime}}{d e_{2}^{\prime}}<1$ and $\frac{d\left(e_{2}^{\prime \prime}-e_{2}^{\prime}\right)}{d e_{2}^{\prime}}<0$. This completes the proof of the proposition."

Our assumption that the marginal cost functions are convex implies that the increase in the marginal cost resulting from a unit increase in the effort level along a dimension is greater when the base effort level along that dimension is higher. Thus, for a given bonus piece rate $\alpha_{1}$ (which denotes the change in the marginal cost in the quantity dimension), the associated change in the effort level is smaller when we start from a higher base effort level along the quantity dimension. As a result, for a given worker, the higher the piece rate component of her base salary is, the smaller is the change in her effort level in the quantity dimension as a result of a given piece rate bonus scheme. A corollary of this result is that, for a given bonus scheme, the increase in production quantity will be greater when the base salary structure is flat rate. 


\section{Experimental Design}

To provide empirical insights into the theory, we ran nine experimental sessions in five Chinese firms between April 2009 and July 2012. All of the firms are located on the southern side of Fujian, a southeastern coastal province of China. The five firms (Hengli, Jiali, Heyu, Wanlida, and Shike) allowed us to introduce treatments pertaining to the production of GPS devices, alarm devices, and clocks. Among the five firms, Hengli, Jiali, and Heyu are clock or clock module manufacturers located in Zhangzhou prefecture. Wanlida is a large electronics manufacturing company whose production center is located in Nanjing county. Shike, a relatively small electronics manufacturer located in Quanzhou city, mainly produces alarm devices.

In our sample, the base salary structure of workers in some of the factories is flat rateworkers receive a fixed hourly wage in Hengli, Wanlida, and Shike. In Jiali and Heyu, on the other hand, workers are paid a piece rate salary possibly with a small flat component. In all firms, within a factory, the base salary scheme of most non-administrative workers follows the same format-flat rate or piece rate. A factory usually chooses a base salary format based on the production process of the main products the factory manufactures. For example, if the production processes are team or product line based, the factories usually choose flat rate salary schemes. If the main products are manufactured individually with stable demands for the products, base salaries are likely to be piece rate. For our experiment, we chose works that are not mainstays of the factories, rather supporting works such as packaging or simple maneuvering that require relatively little training or human capital. Thus, it is unlikely that workers in our experiments have sorted themselves out to a specific kind of base salary structure by their choice of profession. We also note that the piece rate component of the base salary is the same for all workers within a session with a piece rate base salary. Table 1 provides a summary of the nine sessions including the description of the work place and the experimental design described below.

In total, 126 regular employees working in these firms were involved in our experiment. These workers each completed individual tasks: either packaging products (clocks, alarm devices, or attachments to GPS devices) or wedging components into clock modules, or twining metallic threads for clock modules. Within each session, all subjects performed the same task and all workers involved in that specific task were included as subjects in our experiment. For all of the 
tasks, the usual way of quality control is sampling inspection. The sampling rates vary from firm to firm, but none is more than 5\%. Moreover, the factories do not record the exact mapping between a sample product and the worker who produced it. Thus, from the perspective of a worker, the extent of the effort she expends to control the quality of production is more or less unobservable to the managers.

During our experimental sessions, the workers engaged in tasks within their natural work environment unaware of that an experiment was taking place. Accordingly, we denote our experiment as a natural field experiment, following the terminology of Harrison and List (2004). One session typically lasted three days, or around 15 to 24 work hours. For each work hour, we recorded the production and the non-work minutes (if any) for each worker. We then projected the worker's production to her hourly productivity by taking the non-work minutes within the hour into account.

In our setting, a test of the multitasking theory requires the availability of the data on the quality of the workers' productions as well. However, if the workers know that the quality of their production is to be observed, a compounding repeated-game effect would emerge. Our experimental design resolves this dilemma. We chose works that were lightly inspected in the usual production procedure, and hired inspectors to secretly inspect all of the workers' productions and record the number of defects made by each worker for each hour. ${ }^{5}$ To achieve confidentiality, inspection was conducted either in an isolated space away from the workers' workplaces or when all the workers were off duty. Some of the inspections were done after the experimental session was over. We ensured that the inspectors and all the managers involved kept this secret. As noted above, the regular rate of sampling inspection is very low. The workers were unaware of the heightened quality control measures or any change in the inspection process during our experimental sessions.

Depending on the nature of the work, a worker may make more than one defect in a produced unit. For example, each worker in our session at Shike Alarm System Electronic Co. Ltd. was responsible for plugging a circuit wafer into a plastic shell, placing a label on the shell,

\footnotetext{
${ }^{5} \mathrm{~A}$ brief comparison between our design and that of Al-Ubaydli et al (2008) may be worthwhile here. In AlUbaydli et al (2008), temporary workers did not know the inspection procedure conducted by the employer, as there was no well-set procedure in their temporary work environment. By contrast, our experiment took place in the natural workplace of regular factory workers who knew the usual production and inspection procedures very well.
} 
brushing some items, folding the instruction sheet, and then putting all of these items together into a paper box. Workers can potentially commit an error in any of these steps, and each mistake is counted separately. We can calculate the maximum number of possible mistakes or defects a worker can make in a given hour by multiplying the number of units she produces in that hour by the maximum number of defects that can be made for each unit produced. We define the defect rate to be ratio of the number of defects the worker made in that hour and the maximum number of possible defects. Thus, the defect rate takes a value between 0 and 1 .

A session is divided into three rounds: a pre-intervention baseline round was followed by two rounds of interventions. The interventions include the bonus round and the control round. Workers received monetary incentives conditional on their productivity during the bonus round. During the control round, they did not receive any additional monetary incentive. The baseline round lasted three to eight hours. The bonus and control rounds lasted six to eight hours each. Each round typically corresponds to one day. After the baseline round, half of the workers were randomly selected into the bonus group while the others were in the control group. The management notified the subjects of the bonus treatment via personal letters. At the beginning of a round, each worker in the bonus group received a letter saying that she had been selected into a short-term program which lasted for $t$ work hours. For each of the hours, if her productivity exceeded a target of $y$ units, she would receive a bonus at the rate of RMB $\alpha_{1}$ per unit for each unit she produced beyond the target of $y$ units. Thus, if a worker's productivity for a given hour was $x$ units then she would receive no bonus if $x \leq y$ and would receive a bonus of RMB $\alpha_{1}(x-y)$ otherwise. Bonuses, if any, were paid in addition to the workers' base salary. Workers were told that the non-work minutes would be taken into account when measuring hourly productivity to calculate the bonus. Most workers in our experiments were familiar with such a bonus. In peak seasons when they need workers to work harder, the factories sometimes provide piece rate or flat rate bonuses if production exceeds a certain target. The targets, however, are usually based on daily production, not hourly production.

We chose the target $y$ and the piece rate $\alpha_{1}$ based on the baseline data of productivity. Generally speaking, we wanted the target to be difficult to achieve for a worker with average productivity, but she would have a reasonable chance to achieve it if she tried hard. We followed the same formula to choose the parameters so that the target and the piece rate across 
sessions are somewhat comparable. For a session, let $\mathrm{M}$ and SD, respectively, denote the mean and standard deviation of the baseline productivity across all workers in the session. Generally, we chose the target $y$, in consultation with the management in the factories, to be a round number close to $\mathrm{M}+\mathrm{SD}$ that could be considered as a natural target level. ${ }^{6}$ On average, the target was $24 \%$ higher than $\mathrm{M}$ and we observed about $12 \%$ of worker-period combinations in which a worker met the target during a baseline round.

With respect to the setting of the piece rate $\alpha_{1}$, we chose a number that we thought was attractive enough to effectively incentivize even workers with average productivity and would provide almost twice the amount of their average base income as a bonus if they produced at a very high rate, e.g., at two standard deviations above the target level $y$. For example, in session 8, the salary for a worker-subject with average productivity was around RMB 60-65 per day (which approximately equaled USD 10 at the exchange rate during the period of the experiment). Under the bonus round, which lasted for one work day, a worker obtained a bonus of RMB 25, on average, which is approximately $40 \%$ of her base salary. The highest bonus paid in this session was RMB 111, almost double of the average daily salary.

In order to control for the potential effects of receiving a letter, we also sent each worker in the control group a letter which only encouraged her to work hard. ${ }^{7}$ In the second round, we switched the bonus to those subjects who were in the control group in the first round. Those who received the bonus scheme in the first round were in the control group in the second round. The reason for exposing each worker to both bonus and control was twofold. This allows us to identify a worker's effort choices under multitasking consideration using variations within that particular worker. Moreover, as our incentive schemes potentially provided a substantial amount of additional payments to workers, the factories required that we offer the bonus treatments to all workers within a particular set of work. To control for the impact of the treatment sequence, we offered the bonus first to half of the workers and control first to the rest.

A few other experimental particulars of interest are worth noting before we move to the experimental results. First, the source of the bonus was intentionally kept vague. Second, the

\footnotetext{
${ }^{6}$ We made slight adjustments to the target level in order to take outliers in terms of productivity in the baseline hours, if any, into account.

${ }^{7}$ The Appendix includes, as an example, English translation of the letters used in session 5.
} 
letters clearly mentioned that this was a short-term incentive program and the workers were likely to assume that the incentive schemes were one-shot opportunities. Third, during the baseline round, the workers were unaware of the fact that they may receive bonus schemes in the following days; during the first round of experiment, workers in the control group were unaware that they would receive bonus schemes in the next day.

\section{Experimental Results}

In total, the nine experimental sessions included 126 workers. As we collected data on productivity and defects every hour, we have an observation for each hour. We have a total of 2272 observations - 653, 812, and 807 observations under the baseline, bonus, and control rounds, respectively. Table 2 presents summary statistics of hourly productivity, defect rate, and the percentage of hours in which the worker reached the target for the baseline, control, and bonus rounds, for all sessions and sessions with flat rate and piece rate base salary structures separately. Recall that hourly productivity is calculated by projecting a worker's production in a work hour net of the non-work minutes within the hour. The hourly defect rate is defined as the number of defects divided by the maximum possible number of defects for a given hour. Percentage of periods meeting the target reports the ratio of observations in which the worker's productivity was at least as high as the target level set during the bonus round for the session. ${ }^{8}$ As the base productivity and defect rates and the number of hours under each round vary across sessions, the summary statistics aggregating observation from all sessions are not extremely informative. When we look at the sessions under the same base salary structures, the treatment effects are somewhat clearer. Nevertheless, we need to control for session and individual specific heterogeneity to truly identify the treatment effects.

\section{Effect on Productivity}

First, we analyze hourly productivity under the bonus and control rounds compared to the baseline round graphically. Recall that the bonus and control rounds were between six to eight hours long and we have baseline production data for all workers. For each worker, we calculated the percentage deviation in productivity compared to her average productivity in the baseline round for each hour during the bonus and control rounds. Figure 1 presents the percentage

\footnotetext{
${ }^{8}$ Overall, $2.4 \%$ of workers met the target in all periods including the baseline round. Moreover, $28.6 \%$ did not meet the target in any period. The results presented in this paper remain qualitatively unchanged if we exclude these workers from the regressions in Tables 3 to 8.
} 
deviation in productivity from the mean baseline productivity, averaged across all workers, in the first six hours of the bonus and control rounds. Treatment effects vary between experimental sessions. ${ }^{9}$ As a result, when we aggregate the deviation of productivity from the baseline round productivity across workers, we need to ensure that the composition of workers is the same between different hours to keep them comparable. Each of the bonus and control rounds was at least six hours long. Hence, we restrict attention only to the first six hours within a bonus or control round in Figure 1. The figure suggests that both control and bonus rounds increase productivity with the increase being much greater under the bonus scheme. Moreover, the treatment effects do not decrease over time. The figure does not change qualitatively if we present the deviation from the productivity in the last hour the baseline round instead of the deviation from average productivity in the baseline round.

Next, we analyze the data more closely exploiting panel structure of the data set as we have observations over time for each worker. The base estimation model can be described as:

$$
\log \left(\text { productivity }_{i t}\right)=\beta_{1} \times \text { bonus }_{i t}+\beta_{2} \times \text { control }_{i t}+\beta_{3}^{\prime} T_{i t}+c_{i}+\varepsilon_{i t}
$$

where productivity ${ }_{i t}$ denotes hourly productivity of worker $i$ in hour $t$, bonus ${ }_{i t}$ and control $_{i t}$ are dichotomous variables indicating the treatment worker $i$ experienced in hour $t$; and $T_{i t}$ is a vector of variables that control for time effects. The error term consists of time invariant individual specific term $c_{i}$ which controls for heterogeneity among workers, and time variant idiosyncratic individual specific error term $\varepsilon_{i t}$. We allow the term $c_{i}$ to be correlated with other independent variables, in particular $T_{i t}$. Therefore, we present estimates of this model under the fixed effects framework. Nevertheless, we also estimated the model under the random effects framework in the cases where $c_{i}$ is unlikely to be correlated with other independent variables. We assume that $\varepsilon_{i t}$ is independently but not necessarily identically distributed across $i$ and $t$. Therefore, in all of our regression specifications reported below, we use heteroskedasticity-robust standard errors.

\footnotetext{
${ }^{9}$ For example, treatment effects depend critically on the base salary structure and a change in the composition of sessions changes the average deviation of productivity from the mean considerably.
} 
Moreover they are clustered at the worker level, addressing the concern that observations for a worker are not independent across time. ${ }^{10}$

In Table 3, we report the results of this regression under the fixed effects specification. ${ }^{11}$ In column (1) of Table 3, we do not control for any time effect. The column shows that compared to the baseline hours, the bonus scheme increased productivity by $25.6 \%$. Interestingly, the data also show that in the control round, when the workers received an encouraging letter but no monetary incentive, productivity increased by $9.4 \%$ compared to the baseline. Thus, the bonus increased productivity by $16.2 \%$ over the control.

Each of our experimental sessions were run over three days and the workers had already experienced the production processes prior to our experiment. Thus, learning by doing should not be important during our experimental sessions. Nevertheless, as the bonus scheme was new to them, there may still be some learning about how fast they can produce and how to adjust production to this incentive program. In addition, production of any worker may vary over time due to fatigue within a day. As a round typically corresponds to one day, while the $n^{\text {th }}$ work hour within a round may have a different impact on morale and fatigue from the $n-1^{\text {th }}$ work hour in the same round, the impact should be similar to that in the $n^{\text {th }}$ work hour in another round effort costs are likely to be separable across days. To control for this, we create a variable that counts the number of hours under a specific round. That is, this variable starts from one in the baseline round and gets reset to one every time the worker enters a new round - bonus or control. To allow for non-linear time effect within a round, we also create a dummy variable for each work hour within a round. In equation (3), vector $T_{i t}$ contains these time variables. Column (2) includes the time dummy variables as regressors.

Although this approach serves to reduce the coefficient sizes slightly, the bonus and control rounds continue to increase productivity significantly: by $24.8 \%$ and $8.6 \%$, respectively. Importantly, these two coefficients are significantly different from each other with a $p$-value

\footnotetext{
${ }^{10}$ Even though the variation in worker productivity over time across workers within a given session is likely to be independent, for robustness, we also calculated standard errors while clustering at the session level. The main results do not change qualitatively in that case.

${ }^{11}$ The results did not significantly change either qualitatively and quantitatively from those presented in Table 3 when we estimated this model under the random effects specifications. Moreover, the heteroskedasticity and cluster robust Hausman test described in Arellano (1993) rejects the null hypothesis that the random effects estimator is consistent and efficient at significance levels less than $1 \%$.
} 
below 0.0001 . Thus, we conclude that our high-powered incentive scheme had a very large impact in increasing productivity. Specifically, compared to the control, the bonus scheme increased productivity by $16.2 \% .^{12}$

These results are in line with the summary statistics of the proportion of periods in which a worker reached the target, reported in Table 2. This proportion increased to 58.5\% in the bonus round and $36.9 \%$ in the control round from $11.8 \%$ in the baseline round. We also found that the number of workers who met the target more frequently in the bonus round compared to the baseline round is greater than comparable figures for the control round. Likewise, the percentage of workers who always met the target throughout a round indicates a similar effect of treatments: in the baseline round, $3.2 \%$ of workers met the target in all periods, while $46 \%$ and $23 \%$ of workers did so in the bonus control rounds, respectively. Also, the percentage of workers who never met the target in a round decreases: $73 \%$ of workers never met the target in the baseline round while $31 \%$ and $44 \%$ of workers never met the target in the bonus and control rounds, respectively.

\section{Relationship between Productivity and Defect Rate}

Next we analyze how the defect rate is affected by the increase in productivity as reported above. In this way, we are permitted a test of Proposition 1 which is based on the theoretical predictions of Holmstrom and Milgrom (1991) and Baker (1992). First, we test whether the average defect rates in the bonus and control rounds are different from that in the baseline round. Figure 2 presents the average defect rates across all sessions for baseline, control, and bonus rounds: the mean defect rates are $0.009,0.012$, and 0.016, respectively. The difference in defect rates between the control and baseline rounds is statistically significant at the $5 \%$ level, and that between bonus and baseline rounds is statistically significant at the $1 \%$ level. Moreover, the difference in defect rates under bonus and control rounds is significant at $10 \%$ level (the $p$-value is 0.060 ). While the workers increased productivity as a result of the quantity-based bonus scheme, they also reduced the quality of production, as the theory predicts.

\footnotetext{
${ }^{12}$ We have also allowed different sessions to have different time effects, by including session specific time variables but the results did not change significantly.
} 
Table 4 confirms this result by presenting fixed effects panel regressions of log of the defect rate on dummy variables for bonus and control rounds. The base estimation model is described as:

$$
\log \left(\text { defectrate }_{i t}\right)=\Gamma^{\prime} X_{i t}+\beta^{\prime} T_{i t}+c_{i}+\varepsilon_{i t}
$$

where defectrate ${ }_{i t}$ denotes hourly defect rate of worker $i$ at time $t .{ }^{13}$ Moreover, $X_{i t}$ is either a vector containing dummy variables indicating bonus and control rounds or is the log of hourly productivity for worker $i$ at time $t, T_{i t}$ is the time variable vector defined earlier, $c_{i}$ is time invariant individual specific effect for worker $i$, and $\varepsilon_{i t}$ is an idiosyncratic error term. The vector $\Gamma$ contains the coefficients associated with $X_{i t}$.

Column (1) of the table shows that, relative to the baseline round, the bonus scheme statistically significantly increased the defect rate by $61.3 \% .{ }^{14}$ Note that, however, the coefficient for the dummy variable for control round is not statistically significant. Workers increase productivity during control round, perhaps as a result of the encouraging letter they receive, without increasing the defect rate as they have no additional incentive to shift some effort from the quality dimension to the quantity dimension. On the other hand, the piece rate bonus for productivity above the target level provides incentives for shifting effort to the quantity dimension. This results in a greater increase in productivity (relative to the control round) and an increase in the defect rate under the bonus scheme.

Another way of testing the theoretical prediction that workers reduce effort in terms of quality while increasing effort in terms of quantity is to analyze whether the defect rate increases when the worker produces more as is done in Bandiera, Barankay, and Rasul (2005) and Hossain and List (2012). Column (2) of Table 4 presents fixed effects panel regressions of the hourly defect rate on the log of productivity in that hour. A $1 \%$ increase in productivity increases the defect rate by around $1.87 \%$. One might worry about the endogeneity of productivity in this model. However, we controlled for time invariant aspects of endogeneity, such as, for example, highly productive workers inherently having higher or lower defect rates, by estimating it under

\footnotetext{
${ }^{13}$ Since the defect rate for about $25 \%$ of the observations is zero, we added a small value $\left(10^{-7}\right)$ to all observations before taking logarithm of defect rate. The results are robust to the magnitude of this adjustment.

${ }^{14}$ We also estimated this specification using the random effects model. We obtained qualitatively same and quantitatively similar results.
} 
the fixed effects framework, which controls for time-invariant individual specific factor in an error term that may be correlated with productivity. Note that we do not include treatment dummies here, as they are strongly correlated with productivity and including those may confound the effect of productivity on the defect rate. Nevertheless, including those dummies in the regression in column (2) leaves the coefficient of log of productivity virtually unchanged while the coefficients of the dummy variables are small and statistically insignificant.

Together, the two results presented so far are consistent with Proposition 1. In sum, our data provide strong evidence that workers trade off quality for quantity when their income does not depend on quality and they believe that quality is not carefully monitored. ${ }^{15}$ According to the best of our knowledge, this is the first natural field experiment conducted in a regular workplace to find such stark evidence of the most basic theoretical predictions of Holmstrom and Milgrom (1991) and Baker (1992).

\section{Varying the Treatment Effects Depending on the Base Salary Structure}

The base salary structure is different for different sessions within our experiment. Workers in sessions $1,3,4,6$, and 7 are paid by fixed hourly wage rates and workers in sessions 2, 5, 8, and 9 are paid piece rate salaries by their employers. Such richness of our data allows us to investigate whether the base salary structure of the worker has an impact on the treatment effects on quantity and quality of production. With that goal, we run regressions similar to equations (3) and (4), but decompose the treatment dummies by whether the base salary structure is flat rate or piece rate.

Table 5 presents the regression results of log productivity on four dummy variables: bonus and control dummies interacted with the base salary structure of flat rate and piece rate. We present regressions with and without time variables under the fixed effects specification. Column (1) of Table 5 suggests that while the bonus round increases productivity by $50.1 \%$ for the sessions under a flat rate base salary, it increases productivity by only $4.9 \%$ for sessions under a piece rate base salary. Moreover, the control round for sessions with a flat rate base salary increases productivity by $21.1 \%$. Interestingly, the control round does not raise

\footnotetext{
${ }^{15}$ Recall that the workers were completely unaware of the heightened inspection rate and, from their perspectives, there was no change in the monitoring of quality.
} 
productivity over that of the baseline round for the sessions under a piece rate base salary. All of these coefficients are significantly different from each other at conventional significance levels. ${ }^{16}$ Column (2) includes time variables, as in Table 3. The results remain qualitatively the same as those in column (1). Overall, these results are consistent with the prediction regarding the observable effort dimension in Proposition 2. Even though we cannot compare their wage rates directly as the sessions are for different kinds of tasks, the presence of sessions with flat rate and piece rate base salaries allows us to test the predictions of Proposition 2 quite cleanly.

On Table 6, we report results from regressions similar to those in Table 4, but decompose the treatment effects and log productivity based on the base salary structure. In column (1), we find that while the bonus round has a significantly positive effect on the defect rate when the base salary is flat rate, there is no treatment effect for workers under piece rate base salaries. Column (2) suggests similar results in terms of the effect of productivity on the defect rate. For sessions that have a piece rate base salary, there is no statistically significant impact of productivity on the defect rate. For sessions where workers receive a flat rate base salary, however, a $1 \%$ increase in productivity increases the defect rate by $1.70 \%$. This effect is statistically significant.

The above results lead us to qualify the results presented in Tables 3 and 4 by noting that the quantity-quality trade-off occurs only when the workers are not, in the status quo, incented at the margin. A speculative interpretation of these results is that the workers under piece rates might have already been producing near their productivity frontiers, while there is a lot more room for productivity increase under flat rates. Hence, incentives succeed in increasing productivity, but the magnitude is much greater for workers who are currently not incented on the margin. An implication for the body of research that explores incentive effects is that great care must be taken when generalizing empirical results because the extant economic environment (in this case, status quo wage contracts) can greatly influence observed treatment effects.

\footnotetext{
${ }^{16}$ When this specification is estimated under a random effects framework, we obtained both quantitatively and qualitatively similar results but the coefficient for the dummy variable for the control round under a piece rate base salary also becomes statistically significant at $1 \%$. The heteroskedasticity and cluster robust Hausman test rejects the null hypothesis that the random effects estimator is consistent and efficient at significance levels less than $1 \%$.
} 


\section{The Hawthorne Effect}

Table 3 shows that productivity of workers increased by at least $8.6 \%$ during the control round when subjects received no monetary incentive. While the Hawthorne effect has come to take on a very broad definition (see Levitt and List, 2011), we consider the effect in the control round to be consonant with a potential "Hawthorne type" of effect. ${ }^{17}$ However, the control round came after the bonus round for half of the subjects and a strong inertia in productivity may lead to such a result. As these subjects were exposed to a set target level already in the bonus round, that may have also contributed to high productivity during the control round afterwards. To investigate this possibility, we examine the treatment effect for workers who were in the bonus group first and those who were in the control group first, separately. In column (1) of Table 7, we decompose the two treatment dummy variables in terms of whether they received the bonus first or second.

We find that both the workers who received the bonus first and also those who received the control first had productivity increase during the control round: The former group's productivity increases by $8.2 \%$ and the latter group's productivity increases by $9.1 \%$ in the control round relative to the baseline round. Moreover, the differences in the productivity increase between the two groups are not statistically significant. Hence, the productivity increase under the control round cannot be attributed to positive inertia of the workers who received the bonus first. ${ }^{18}$ The large productivity increase during the control round for workers receiving control first also suggests that the Hawthorne effect did not merely arise from some positive time trend in productivity. ${ }^{19}$

In Table 5, we found that the control round led to productivity increase only for workers under the flat rate base salary structure. We present regressions with only the workers under flat rate and piece rate base salaries in columns (2) and (3) of Table 7, respectively. The coefficient for the control round dummies are statistically significant only in column (2): under the flat rate base wage, a $16.4 \%$ productivity increase for workers who received bonus in the first round and a $21.6 \%$ productivity increase for those who received control in the first round. Therefore, we

\footnotetext{
${ }^{17}$ The workers under the control round received an encouraging letter that accords attention to them.

${ }^{18}$ We ran similar regressions for the log defect rate. We did not find evidence to suggest that workers changed their production quality statistically significantly during the control round relative to the baseline round for either the workers who received bonus first or those who received control first.

${ }^{19}$ This stays unchanged if we include a time variable that does not reset to 1 when a new round starts.
} 
find a Hawthorne effect for workers under a flat rate base salary structure, but not for those under a piece rate base salary structure. ${ }^{20}$ Although close inspection of the original data suggests that there was no Hawthorne effect in the Western Electric's Hawthorne Plant in Cicero, IL, USA (Levitt and List, 2011 and the cites therein), we find a strong Hawthorne effect among factory workers under a flat rate base salary structure in Fujian, China. While Leonard (2008) and Leonard and Masatu (2006 and 2010) find significant evidence of the Hawthorne effect in terms of the quality of health service, as far as we know, our paper presents the first verified evidence of a large Hawthorne effect among factory workers.

\section{Persistence of the Hawthorne Effect}

We use a conditional bonus scheme in this experiment. Unlike the experiments where the incentive effect of an unconditional bonus is short lived (see, Gneezy and List, 2006, for example), we expect the impact of our bonus to persist. We can test whether that is indeed the case. One may also wonder whether the Hawthorne effect of productivity increase in the control group is short lived, as the positive impact on productivity received from the encouraging letter may die down quickly.

The first evidence of persistence of the Hawthorne effect is seen in Figure 1, where we do not see any evidence of waning in the incentive effect or the Hawthorne effect over time. We also devise an additional test taking advantage of the panel structure of our data set. We divide the bonus and control rounds into two halves. For example, both bonus and control rounds for session 1 were seven hours long. Then, the first 4 hours are considered to be in the first half and the following three hours are considered to be in the second half. We look at the impact of the bonus and control rounds dividing each of them into two halves in column (1) of Table 8. If any of the treatment effects is short-lived then the coefficient for that treatment dummy will be much smaller in the second half of that treatment. Our regressions find that not to be the case. The productivity increase during the first half of bonus round relative to the baseline round is $25.1 \%$, while that during the second half is $26.2 \%$. Also, the productivity increase in the first half of the control round relative to the baseline round is $8.6 \%$ while that in the second half is $10.2 \%$. Thus, the coefficients for the second half is larger than that for the first half although the differences

\footnotetext{
${ }^{20}$ This is likely to be related to the fact that the productivities of the workers under a flat rate base salary structure in the baseline round seem to have been far below their production frontiers.
} 
are not statistically significant, for both bonus and control rounds. We do not include any time variable here because that will dilute any potential difference in treatment effects between the two halves of a treatment. Hence, the Hawthorne effect in our experiment was persistent and not short lived.

\section{Conclusions}

Principal-agent models have become the workhorse framework for modeling asymmetric information settings. In the field, when the agent cannot be certain that a dimension of output is closely monitored, the classic multitasking theory applies. This study provides empirical insights into the multitasking problem by making use of a unique naturally-occurring setting: incentive contracts for workers in China on the floor of various factories. Through our interactions with managers at the plants, we were able to implement a natural field experiment in several plants to explore basic questions within the classic principal-agent setting.

Our main results paint an intriguing picture. First, the first order predictions of the theory are found in our data: as we incent workers on the margin, they move their effort to the incented activity to the detriment of the non-incented one. But, there is an important caveat to this result: we only find this result amongst workers who were previously working under a fixed wage scheme. For those workers previously under a piece rate scheme, their output moves by a small magnitude when we introduce a performance incentive. Our results suggest that, in structural estimation of principal agent models, simplification of the model into a single task dimension when the task is better described by multiple dimensions may yield biased estimates of structural parameters.

Second, we report an interesting Hawthorne-type effect. We find that a simple reminder letter to workers leads to a robust and economically significant increase in worker productivity. In this way, the data are consonant with a Hawthorne effect in Chinese manufacturing plants. Notably, while the actual Hawthorne data from the original experiments do not stand up to closer scrutiny, data from the Chinese factories do. Finally, an overarching lesson learned from this exercise is that one can gain enough control in a field environment to test important theories of multitasking incentive schemes. 


\section{Reference}

Al-Ubaydli, Omar, S. Anderson, Uri Gneezy and J.A. List (2008): "For Love or Money? Comparing the Effects of Non-pecuniary and Pecuniary Incentive Schemes in the Workplace,” working paper, University of Chicago.

Arellano, Manuel (1993): “On the Testing of Correlated Effects with Panel Data,” Journal of Econometrics, 59, 87-93.

Baker, George P. (1992): “Incentive Contracts and Performance Measurement," Journal of Political Economy, 100 (3), 598-614.

Baker, George P., Michael C. Jensen, and Kevin J. Murphy (1988): "Compensation and Incentives: Practice vs. Theory,” Journal of Finance, 43 (3), 593-616.

Bandiera, Oriana, Iwan Barankay, and Imran Rasul (2005): "Social Preferences and the Response to Incentives: Evidence from Personnel Data,” Quarterly Journal of Economics, 120 (3): 917-962.

Dumont Etienne, Bernard Fortin, Nicolas Jacquemet, and Bruce Shearer (2008): "Physician's Multitasking and Incentives: Empirical Evidence from a Natural Experiment,” Journal of Health Economics, 27 (6), 1436-1450.

Englmaier, Florian, Andreas Roider, and Uwe Sunde (2013): “The Role of Salience in Performance Schemes: Evidence from a Field Experiment,” working paper, LMU Munich.

Gneezy, Uri and John A. List (2006): "Putting Behavioral Economics to Work: Testing for Gift Exchange in Labor Markets Using Field Experiments,” Econometrica, 74 (5), 1365-1384.

Griffith, Rachel, and Andrew Neely (2009): "Performance Pay and Mangerial Experience in Multitask Teams: Evidence from within a Firm,” Journal of Labor Economics, 27 (1), 4982.

Harrison, Glenn W., and John A. List (2004): “Field experiments,” Journal of Economic Literature, 42 (4), 1009-1055.

Hartocolis, Anemona (2013): “New York City Ties Doctor’s Income to Quality of Care,” The New York Times, January 11, 2013.

Holmstrom, Bengt and Paul Milgrom (1991): "Multitask Principal-Agent Analyses: Incentive Contracts, Asset Ownership and Job Design,” Journal of Law, Economics and Organization, 7, 24-52.

Hossain, Tanjim and King King Li (2013): “Social Preference as an Incentive Device: Some Hidden Costs,” forthcoming, Management Science. 
Hossain, Tanjim and John A. List (2012): "The Behavioralist Visits the Factory: Increasing Productivity Using Simple Framing Manipulations,” Management Science, 57 (12), 21512167.

Jensen, Michael (2001): "Value Maximization, Stakeholder Theory, and the Corporate Objective Function,” Journal of Applied Corporate Finance, 14 (3), 8-21.

Johnson, Ryan M., David H. Reiley, and Juan Carlos Munoz (2012): "The War for the Fare: How Driver Compensation Affects Bus System Performance,” working paper, University of Arizona.

Keller, Bill (2013): “Carrots for Doctors,” The New York Times, January 27, 2013.

Leonard, Kenneth L. (2008): "Is Patient Satisfaction Sensitive to Changes in the Quality of Care? An Exploitation of the Hawthorne Effect,” Journal of Health Economics, 27 (2), 444-459.

Leonard, K.L. and M.C. Masatu (2006): "Outpatient Process Quality Evaluation and the Hawthorne Effect,” Social Science \& Medicine, 63 (9), 2330-2340.

Leonard, K.L. and M.C. Masatu (2010): "Using the Hawthorne Effect to Examine the Gap between a Doctor's Best Possible Practice and Actual Practice," Journal of Development Economics, 93 (2), 226-243.

Levitt, Steve and John A. List (2011): "Was There Really a Hawthorne Effect at the Hawthorne Plant? An Analysis of the Original Illumination Experiments," American Economic Journal: Applied Economics, 3 (1), 224-238.

Lu, Feng (2012): "Multitasking, Information Disclosure and Product Quality: Evidence from Nursing Homes," Journal of Economic and Management Strategy, 21 (3), 673-705

Marschke, J. (1996): “Incentives in a Government Bureaucracy,” mimeo, University of Chicago.

Paarsch, Harry and Bruce Shearer (2000): "Piece Rates, Fixed Wages and Incentives Effects: Statistical Evidence from Payroll Records,” International Economic Review, 41 (1), 59-92.

Prendergast, Canice (1999): “The Provision of Incentives in Firms,” Journal of Economic Literature, 37 (1), 7-63.

Shearer, Bruce (2004): "Piece Rates, Fixed Wages and Incentives: Evidence from a Field Experiment,” Review of Economic Studies, 71 (2), 513-34.

Slade, Margaret (1996): "Multitask Agency and Contract Choice: An Empirical Exploration,” International Economic Review, 37 (2), 465-486. 


\section{Appendix}

\section{Translation of Letters Sent to the Workers in Session 5}

The letter used for the treatment group

Hello, Name of the worker.

Thanks for your unceasing hard work. We are glad to let you know that you have been chosen into a short-term program. In the following 7 working hours today, for the current clock-wedging job, we will count your production after each working hour. In any of the working hour, for the part of your production exceeding 700 units, you will receive a reward at the rate of RMB 0.2 per unit. We will take into account the non-work minutes when calculating your productivity. The payment will be made in early June.

For example, during the hour of 9-10 am, you produce 720 units with 3 non-work minutes. Then in this hour, you will obtain a reward payment for the following amount:

$[720 \times 60 /(60-3)-700] \times 0.2=$ RMB 11.6

The reward for each working hour today will be calculated in the similar way. This reward scheme only lasts for today.

Warm regards.

The letter used for the control group

Hello, Name of the worker.

Thanks for your unceasing hard work.

Warm regards. 
Figure 1: Percentage Deviation from Mean Baseline Productivity during Bonus and Control Rounds

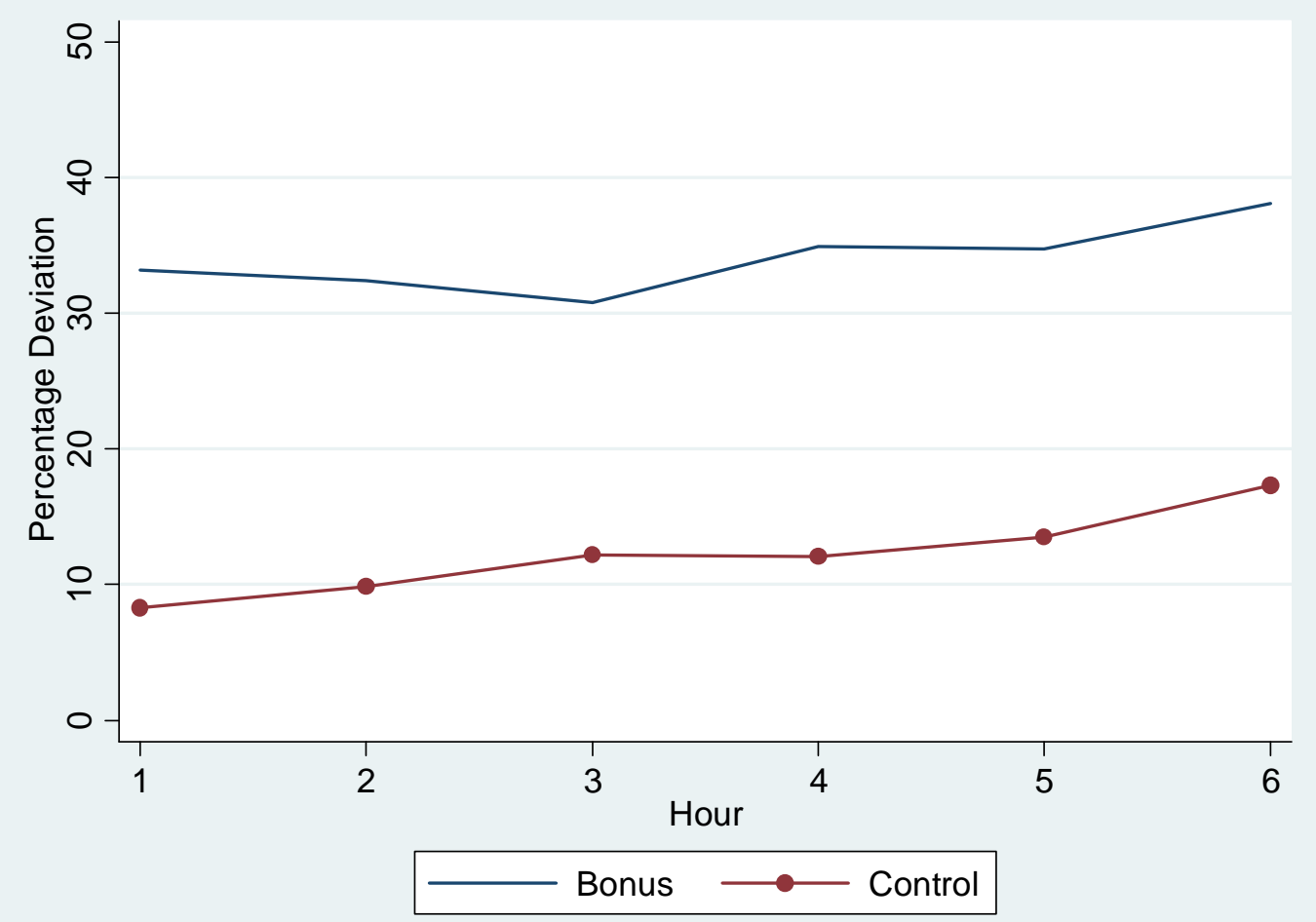

Figure 2: Average Defect Rates across All Sessions under Different Treatments

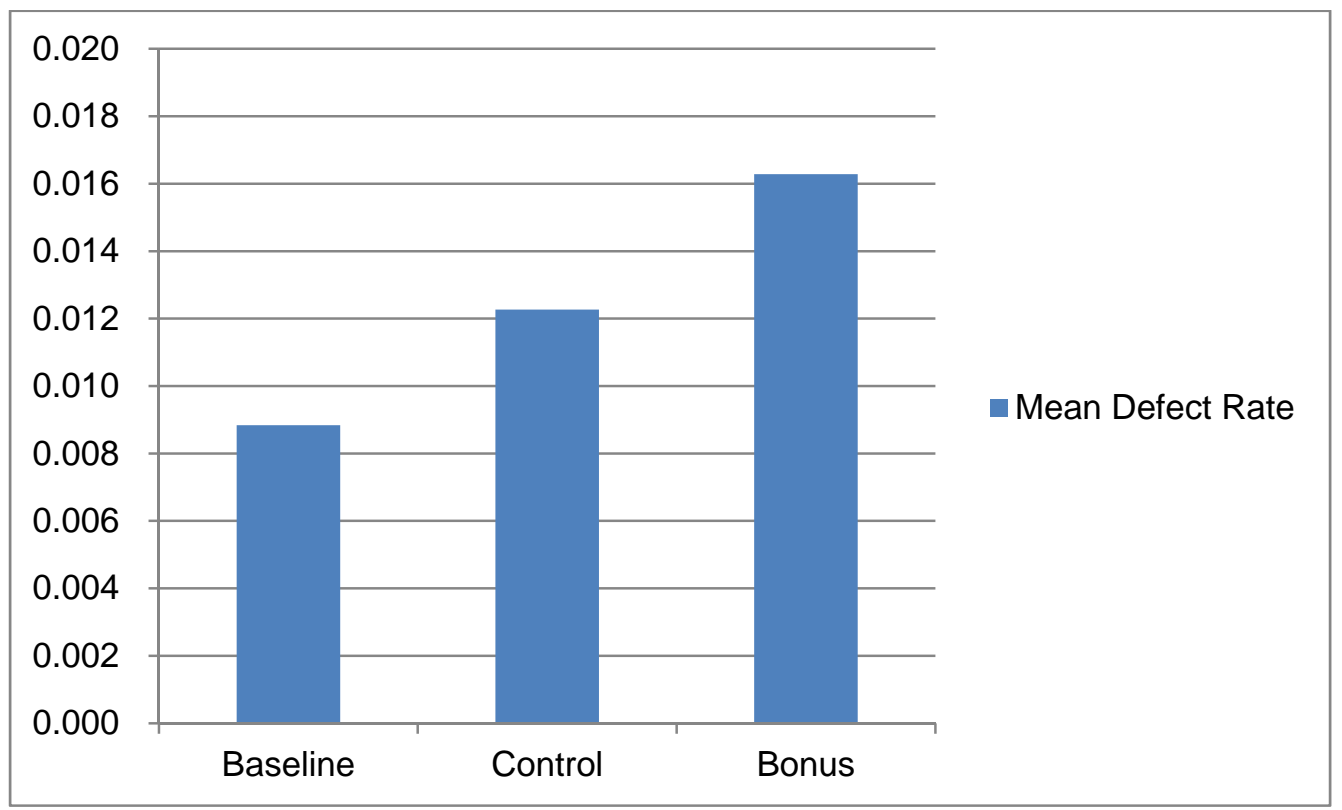


Table 1: A Summary of Experimental Design

\begin{tabular}{|c|c|c|c|c|c|c|c|c|c|c|}
\hline \multirow[b]{2}{*}{ Session } & \multirow[b]{2}{*}{ Company } & \multirow[b]{2}{*}{ Task } & \multirow[b]{2}{*}{$\begin{array}{l}\text { Base Salary } \\
\text { Structure }\end{array}$} & \multirow[b]{2}{*}{$\begin{array}{l}\text { Number of } \\
\text { Subjects }\end{array}$} & \multirow{2}{*}{$\begin{array}{l}\text { Baseline } \\
\text { Round } \\
\text { Duration } \\
\text { (Hours) }\end{array}$} & \multirow{2}{*}{\begin{tabular}{|c|} 
Bonus/Control \\
Round \\
Duration \\
(Hours) \\
\end{tabular}} & \multirow{2}{*}{$\begin{array}{c}\text { Mean } \\
\text { Baseline } \\
\text { Productivity }\end{array}$} & \multirow[b]{2}{*}{$\begin{array}{l}\text { SD Baseline } \\
\text { Productivity }\end{array}$} & \multicolumn{2}{|c|}{ Bonus Scheme } \\
\hline & & & & & & & & & Target $(y)$ & $\begin{array}{c}\text { Piece Rate }\left(\alpha_{1}\right) \\
\text { (RMB/unit) }\end{array}$ \\
\hline 1 & $\begin{array}{l}\text { Wanlida (Wanlida } \\
\text { Group Co.) }\end{array}$ & $\begin{array}{c}\text { GPS } \\
\text { attachment } \\
\text { packaging }\end{array}$ & Flat Rate & 15 & 5 & 7 & 95.1 & 18.74 & 120 & 1.25 \\
\hline 2 & $\begin{array}{c}\text { Jiali (Zhangzhou } \\
\text { Jiali Electronic Co., } \\
\text { Ltd.) }\end{array}$ & $\begin{array}{c}\text { Clock } \\
\text { component } \\
\text { wedging }\end{array}$ & Piece Rate & 14 & 8 & 8 & 608 & 96.5 & 700 & 0.2 \\
\hline 3 & $\begin{array}{l}\text { Shike (Shike Alarm } \\
\text { System Electronic } \\
\text { Co., Ltd.) }\end{array}$ & $\begin{array}{c}\text { Alarm device } \\
\text { packaging }\end{array}$ & Flat Rate & 10 & 4 & 6 & 24 & 6.9 & 33 & 1 \\
\hline 4 & Wanlida & $\begin{array}{c}\text { GPS } \\
\text { attachment } \\
\text { packaging }\end{array}$ & Flat Rate & 14 & 3 & 6 & 121.8 & 17.9 & 150 & 0.6 \\
\hline 5 & Jiali & $\begin{array}{c}\text { Clock } \\
\text { component } \\
\text { wedging }\end{array}$ & Piece Rate & 17 & 6 & 7 & 597 & 113 & 700 & 0.2 \\
\hline 6 & $\begin{array}{l}\text { Hengli (Zhangzhou } \\
\text { Hengli Electronic } \\
\text { Co., Ltd.) }\end{array}$ & $\begin{array}{l}\text { Wall clock } \\
\text { packaging }\end{array}$ & Flat Rate & 10 & 6 & 7 & 30.6 & 7.7 & 40 & 0.8 \\
\hline 7 & Hengli & $\begin{array}{l}\text { Wall clock } \\
\text { packaging }\end{array}$ & Flat Rate & 15 & 4 & 6 & 62.1 & 10.9 & 85 & 0.5 \\
\hline 8 & Jiali & $\begin{array}{c}\text { Clock } \\
\text { component } \\
\text { wedging }\end{array}$ & Piece Rate & 21 & 6 & 6 & 503.4 & 98 & 620 & 0.3 \\
\hline 9 & $\begin{array}{l}\text { Heyu (Zhangzhou } \\
\text { Heyu Electronic } \\
\text { Co., Ltd) }\end{array}$ & \begin{tabular}{|c|} 
Twining \\
metallic \\
threads in a \\
clock module
\end{tabular} & Piece Rate & 10 & 5 & 6 & 569 & 97 & 700 & 0.15 \\
\hline
\end{tabular}


Table 2: Summary Statistics

\begin{tabular}{|c|c|c|c|c|c|c|c|c|c|}
\hline & \multicolumn{3}{|c|}{ All Sessions } & \multicolumn{3}{|c|}{ Flat Rate Base Salary } & \multicolumn{3}{|c|}{ Piece Rate Base Salary } \\
\hline & Baseline & Control & Bonus & Baseline & Control & Bonus & Baseline & Control & Bonus \\
\hline \multirow{2}{*}{ Hourly Productivity } & 355.9 & 336.4 & 358.3 & 67.8 & 89.4 & 117.1 & 568.1 & 575.5 & 594.7 \\
\hline & $(262.5)$ & $(257.5)$ & $(253.3)$ & $(37.7)$ & $(51.0)$ & (61.8) & $(110.6)$ & $(107.7)$ & $(101.4)$ \\
\hline \multirow{2}{*}{ Hourly Defect Rate } & 0.009 & 0.012 & 0.016 & 0.019 & 0.024 & 0.032 & 0.001 & 0.001 & 0.001 \\
\hline & $(0.018)$ & $(0.033)$ & $(0.051)$ & $(0.024)$ & $(0.045)$ & $(0.069)$ & $(0.002)$ & $(0.002)$ & $(0.002)$ \\
\hline $\begin{array}{l}\text { Percentage of Periods } \\
\text { Meeting the Target } \\
\end{array}$ & $11.8 \%$ & $36.9 \%$ & $58.5 \%$ & $7.9 \%$ & $51.1 \%$ & $87.1 \%$ & $14.6 \%$ & $23.2 \%$ & $30.5 \%$ \\
\hline Number of Workers & 126 & 126 & 126 & 64 & 64 & 64 & 62 & 62 & 62 \\
\hline Observations & 653 & 807 & 812 & 277 & 397 & 402 & 376 & 410 & 410 \\
\hline
\end{tabular}

Note: The top number in each cell denotes the mean and the bottom number, in parentheses, denotes standard deviation. 
Table 3: Treatment Effect on Productivity

\begin{tabular}{ccc}
\hline \hline & \multicolumn{2}{c}{ Dependent Variable: log of Hourly } \\
Productivity & $(\mathbf{1})$ & (2) \\
\hline \multirow{2}{*}{ Bonus } & $0.256^{* * *}$ & $0.248^{* * *}$ \\
& $(0.025)$ & $(0.024)$ \\
Control & $0.094^{* * *}$ & $0.086^{* * *}$ \\
& $(0.017)$ & $(0.016)$ \\
\hline \multirow{2}{*}{ Time Variables Included } & No & \multirow{2}{*}{ Yes } \\
Observations & 2272 & 2272 \\
$\mathrm{R}^{2}$ & 0.271 & 0.285 \\
\hline \hline
\end{tabular}

Notes: This table presents fixed effects panel regressions of log hourly productivity on dummy variables denoting bonus and control rounds. In column (2), dummy variables denoting the hour within a round are included to control for time effects. Hetero-skedasticity robust standard errors are presented inside parentheses. ${ }^{*}, * *$, and ${ }^{* * *}$ represent significance at $10 \%, 5 \%$, and $1 \%$ levels, respectively. 
Table 4: Treatment Effect on the Defect Rate

\begin{tabular}{ccc}
\hline \hline & $\begin{array}{c}\text { Dependent Variable: log of Hourly Defect Rate } \\
(\mathbf{1})\end{array}$ \\
\hline (2)
\end{tabular}

Notes: This table presents fixed effects panel regressions of the hourly defect rate on dummies denoting bonus and control rounds or log of hourly productivity. Under both specifications, dummy variables denoting the hour within a round are included to control for time effects. Heteroskedasticity robust standard errors are presented inside parentheses. *, **, and *** represent significance at $10 \%, 5 \%$, and $1 \%$ levels, respectively. 
Table 5: Varying Treatment Effect According to the Base Salary Structure

\begin{tabular}{ccc}
\hline \hline & $\begin{array}{c}\text { Dependent Variable: log of Hourly Productivity } \\
\text { (1) }\end{array}$ \\
\hline Bonus $\times$ The Base Salary is Flat & $0.501^{* * *}$ & $0.492^{* * *}$ \\
Rate & $(0.028)$ & $(0.028)$ \\
Control $\times$ The Base Salary is Flat & $0.211^{* * *}$ & $0.202^{* * *}$ \\
Rate & $(0.027)$ & $(0.027)$ \\
Bonus $\times$ The Base Salary is Piece & $0.049^{* * *}$ & $0.047^{* * *}$ \\
Rate & $(0.013)$ & $(0.013)$ \\
Control $\times$ The Base Salary is Piece & 0.012 & 0.010 \\
Rate & $(0.011)$ & $(0.011)$ \\
\hline Time Variables Included & No & Yes \\
Observations & 2272 & 2272 \\
$\mathrm{R}^{2}$ & 0.476 & 0.482 \\
\hline \hline
\end{tabular}

Notes: This table presents fixed effects panel regressions of log hourly productivity on dummy variables denoting bonus and control rounds interacted with dummy variables indicating the base salary structure. In column (2), dummy variables denoting the hour within a round are included to control for time effects. Heteroskedasticity robust standard errors are presented inside parentheses. *, **, and $* * *$ represent significance at $10 \%, 5 \%$, and $1 \%$ levels, respectively. 
Table 6: Impact of Base Salary Structure on the Defect Rate

\begin{tabular}{ccc}
\hline \hline & $\begin{array}{c}\text { Dependent Variable: log of Hourly Defect Rate } \\
(\mathbf{1})\end{array}$ & $(\mathbf{2})$ \\
\hline Bonus $\times$ The Base Salary is Flat & $0.972^{* * *}$ & $(0.359)$ \\
Rate & 0.002 & \\
Control $\times$ The Base Salary is Flat & $(0.444)$ & \\
Rate & 0.312 & \\
Bonus $\times$ The Base Salary is Piece & $(0.450)$ & $1.696^{* * *}$ \\
Rate & -0.173 & $(0.485)$ \\
Control $\times$ The Base Salary is Piece & $(0.416)$ & 3.840 \\
Rate & & $(2.369)$ \\
$\log ($ Productivity) $\times$ The Base Salary & & 2272 \\
is Flat Rate & & 0.0103 \\
$\log ($ Productivity) $\times$ The Base Salary & & \\
is Piece Rate & 2272 & \\
\hline Observations & 0.009 & \\
$\mathrm{R}^{2}$ & & \\
\hline \hline
\end{tabular}

Notes: This table presents fixed effects panel regressions of the hourly defect rate on bonus and control dummies and log productivity decomposed with respect to the base salary structure. Under both specifications, dummy variables denoting the hour within a round are included to control for time effects. Hetero-skedasticity robust standard errors are presented inside parentheses. *, **, and *** represent significance at $10 \%, 5 \%$, and $1 \%$ levels, respectively. 


\section{Table 7: The Hawthorne Effect}

\begin{tabular}{|c|c|c|c|}
\hline & \multicolumn{3}{|c|}{ "Dependent Variable: log of Hourly Productivity } \\
\hline & (1) & (2) & (3) \\
\hline Bonus $\times$ The Worker Received Bonus & $0.207^{* * *}$ & $0.347^{* * *}$ & $0.079^{* * *}$ \\
\hline First & $(0.023)$ & $(0.022)$ & $(0.020)$ \\
\hline Control $\times$ The Worker Received Bonus & $0.082^{* * *}$ & $0.164^{* * *}$ & 0.015 \\
\hline First & $(0.023)$ & $(0.039)$ & $(0.018)$ \\
\hline Bonus $\times$ The Worker Received Control & $0.290^{* * *}$ & $0.622^{* * *}$ & 0.021 \\
\hline First & $(0.044)$ & $(0.038)$ & $(0.015)$ \\
\hline Control $\times$ The Worker Received Control & $0.091^{* * *}$ & $0.216^{* * *}$ & 0.010 \\
\hline First & $(0.022)$ & $(0.036)$ & $(0.014)$ \\
\hline Sessions Included & All & Flat rate Base Salary Only & Piece rate Base Salary Only \\
\hline Observations & 2272 & 1076 & 1196 \\
\hline $\mathrm{R}^{2}$ & 0.295 & 0.574 & 0.117 \\
\hline
\end{tabular}

Notes: This table presents fixed effects panel regressions of log hourly productivity on dummy variables denoting bonus and control rounds interacted with dummies to indicate whether the bonus treatment was used first or second. Column (1) presents result with all sessions. Columns (2) and (3), respectively, use sessions with flat rate and piece rate base salary only. Under all specifications, dummy variables denoting the hour within a round are included to control for time effects. Hetero-skedasticity robust standard errors are presented inside parentheses. *, **, and *** represent significance at $10 \%, 5 \%$, and $1 \%$ levels, respectively. 
Table 8: Persistence of the Hawthorne Effect

\begin{tabular}{cc}
\hline \hline & $\begin{array}{c}\text { Dependent Variable: log of } \\
\text { Hourly Productivity }\end{array}$ \\
\hline First Half of Bonus & $0.251^{* * *}$ \\
Second Half of Bonus & $0.025)$ \\
& $0.262^{* * *}$ \\
First Half of Control & $0.027)$ \\
& $0.086^{* * *}$ \\
Second Half of Control & $(0.017)$ \\
& $0.102^{* * *}$ \\
\hline p-value from F-test: Bonus in both halves & $(0.018)$ \\
have the same coefficient & 0.2956 \\
p-value from F-test: Control in both & 0.1075 \\
halves have the same coefficient & 2272 \\
Observations & 0.272 \\
$\mathrm{R}^{2}$ & \\
\hline \hline
\end{tabular}

Notes: This table presents fixed effects panel regressions of log hourly productivity on dummies denoting bonus and control rounds and those dummies divided into two halves. Hetero-skedasticity robust standard errors are presented inside parentheses. $*, * *$, and $* * *$ represent significance at $10 \%, 5 \%$, and $1 \%$ levels, respectively. 